\title{
Potensi Ekstrak Daun Pepaya sebagai Inhibitor Korosi dalam Media Asam Klorida pada Baja ST37
}

\author{
Dwi Kemala Putri ${ }^{1}$, Addin Akbar ${ }^{1}$

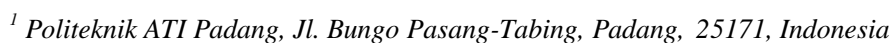

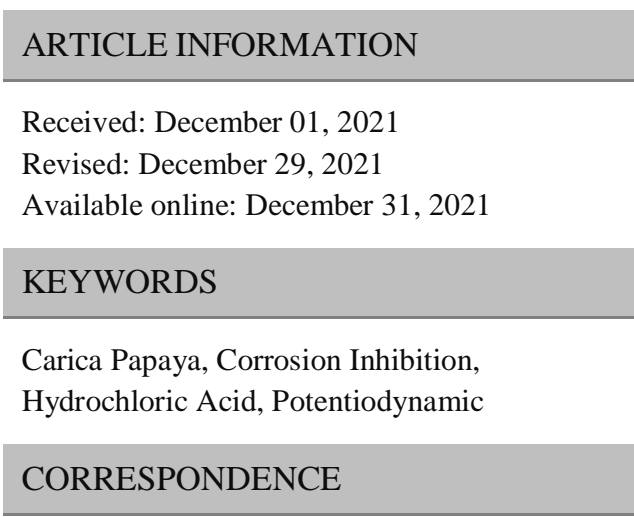

Name: Dwi Kemala Putri

E-mail: dwikemala@poltekatipdg.ac.id

\begin{abstract}
A B S T R A C T
Corrosion is a decrease in the quality of a metal material caused by a reaction with the environment. Reducing the corrosion rate on steel can be done by adding an inhibitor. Papaya leaf extract (Carica papaya.L) can be used as a corrosion inhibitor by immersion method. The effect of inhibitor on corrosion rate had been studied using weight loss method, potentiodynamic polarization method, and observation of steel surface using photooptic. It was found that corrosion rate decrease with increase concentration of papaya leaves extract. The highest inhibiton efficiency is $87.8 \%$ in $0.2 \mathrm{M}$ hydrochloric acid with $2 \%$ concentration of papaya leaves extract. Potentiodynamic polarization method showed that papaya leaves extract decrease corrotion current. Inhibiton efficiency reached $81.58 \%$ in $2 \%$ extract concentration in which corrosion current decrease from $0.0266 \mathrm{~mA} / \mathrm{cm} 2$ to $0.0049 \mathrm{~mA} / \mathrm{cm} 2$. Analysis of photooptic showed that there is difference on steel surface corroded in hydrochloric acid with inhibitor and without it.
\end{abstract}

\section{PENDAHULUAN}

Korosi adalah proses terkikisnya suatu material logam dikarenakan reaksi elektrokimia antara logam dengan kondisi lingkungan sekitar logam [1]. Salah satu resiko dari korosi adalah terjadinya penurunan sifat mekanik dari material logam sehingga mengakibatkan kerugian dalam segi ekonomi dan faktor keselamatan [2]. Penggunaan baja sebagian besar diaplikasikan pada mesin dan peralatan logam lainnya, sehingga diharapkan memiliki kekuatan dan ketangguhan yang baik, agar pada saat digunakan dapat menahan beban dan bertahan lama dalam waktu pengoperasian [3]. Akan tetapi, salah satu kelemahan dalam penggunaan baja karbon adalah kandungan asam-asam mineral dengan reaktifitas yang cukup tinggi yang juga dapat menyebabkan terjadinya korosi [4]. Korosi merupakan permasalahan serius dalam industri sehingga menarik perhatian para peneliti untuk menciptakan material tahan korosi ataupun bahan pencegah korosi. Dalam beberapa proses industri seperti pembersihan dengan asam, etsa, dan pickling menggunakan medium agresif seperti asam, basa dan garam, sehingga logam akan terkorosi. Dengan demikian, korosi dianggap merugikan terutama dibidang industri yang biasa menggunakan alat-alat berat, sebab proses korosi mengakibatkan penurunan kekuatan material, sehingga meningkatkan biaya perawatan dan perbaikan atau pergantian alat. Menurut Faizal dkk pada penelitian terdahulu, yaitu melihat pengaruh air laut terhadap ketahanan pada baja rendah karbon. Dari hasil penelitian Faizal dkk, menyatakan salah satu penyebab peningkatan laju korosi adalah tingkat keasaman dalam air. Faizal menyatakan bahwa semakin tinggi tingkat keasaman dalam air maka akan meningkatkan jumlah zat yang terlarut sehingga akan meningkatkan laju korosi dari baja tersebut [5].

Korosi logam memang tidak dapat dihindari namun dapat ditunda waktunya dengan metode tertentu. Beberapa cara telah dilakukan untuk dapat mengurangi korosi terhadap instalasi industri diantaranya adalah dengan proteksi katodik, pelapisan (coating) sehingga dapat menggurangi kontak antara logam dengan lingkungan sekitar. Salah satu yang paling efektif yaitu dengan menggunakan penambahan inhibitor korosi [4]. Telah dilaporkan melalui beberapa penelitian bahwa senyawa sintetik terbukti cukup efektif sebagai inhibitor korosi material 
logam. Namun, penggunaan inhibitor korosi sintetik saat ini belum cukup luas dikarenakan adanya peraturan lingkungan yang ketat serta sifat racun dari inhibitor yang berbahaya bagi kehidupan manusia dan hewan. Oleh karena itu, perlu diperlukan penelitian lanjutan dalam pengembangan inhibitor korosi sehingga akan dihasilkan inhibitor korosi yang ramah lingkungan, biodegradable, murah, tidak beracun, serta memiliki efisiensi yang baik [6].

Ekstrak tanaman selain jumlahnya yang melimpah juga bersifat tidak beracun. Kandungan kimia dari ekstrak tanaman seperti flavonoid, polifenol, dan polisakarida berpotensi menghambat korosi pada logam [7]. Ekstrak daun tembakau dapat digunakan sebagai inhibitor korosi pada logam baja karbon dan aluminium [1]. Beberapa hasil penelitian menunjukkan bahwa ekstrak tanaman seperti ekstrak kulit jeruk, bamboo, Nigella sativa, dau n ginkgo, buah lychee mengandung senyawa organik kompleks seperti tannin, alkaloid, flavonoid, dan basa nitrogen. Senyawa organik tersebut memilki kandungan heteroatom (N, S, dan O), gugus elektronegatif, serta ikatan rangkap konjugasi sebagai pusat adsorpsi utama dari inhibitor korosi [8]. Menurut A'yun dkk, yang telah melakukan analisis fitokimia terhadap daun papaya menyatakan bahwa daun papaya positif mengandung tannin, yang dapat digunakan sebagai inhibitor korosi. [9] Berdasarkan hal ini perlu dilakukan penelitian untuk pemanfaatan ekstrak daun papaya sebagai inhibitor korosi.

\section{METODOLOGI}

\section{Alat dan Bahan}

Bahan baku yang digunakan pada penelitian ini adalah baja ST37, daun papaya, aseton, $\mathrm{HCl}$, aquadest, methanol, dan $\mathrm{FeCl}_{3}$. Alat yang digunakan adalah neraca analitik, dan alat-alat gelas. Baja ST37 dengan diameter $\pm 2.5 \mathrm{~cm}$ dan ketebalan $\pm 0.5 \mathrm{~cm}$ dihaluskan permukaannya dengan menggunakan ampelas besi dan dibilas dengan aquadest. Baja direndam dalam aseton untuk menghilangkan kemungkinan lemak yang menempel, dan selanjutnya dikeringkan dalam oven suhu $60^{\circ} \mathrm{C}$. Setelah kering baja ditimbang dan hasil penimbangan dinyatakan sebagai berat awal $\left(\mathrm{m}_{1}\right)$.

Pembuatan medium korosif dengan membuat induk larutan $\mathrm{HCl}$ dengan konsentrasi $2 \mathrm{M}(\mathrm{v} / \mathrm{v})$. Larutan $\mathrm{HCl}$ untuk pengujian dibuat bervariasi dengan konsentrasi $0.2 \mathrm{M} ; 0.6 \mathrm{M}$; dan 1.0M.

Pembuatan ekstrak daun papaya dengan mengeringkan daun papaya segar sampai kering, sebanyak $1 \mathrm{~kg}$ pepaya kering dihaluskan dan diekstrak menggunakan metode maserasi dengan pelarut methanol. Proses maserasi dilakukan selama 3 hari. Proses maserasi dilakukan dengan perbandingan 1:3 (b/v) menggunakan methanol 90\% (pro analis). Ekstrak yang didapat disaring dan diuapkan pelarutnya dengan menggunakan Rotary Evaporator. Ekstrak pekat disimpan dan nantinya digunakan sebagai larutan ekstrak untuk inhibisi korosi. Larutan induk ekstrak pekat dibuat sebesar 5\% (b/v).

\section{Rancangan Penelitian}

Baja ST 37 direndam ke dalam variasi larutan medium korosi yaitu $0,2 \mathrm{M} ; \quad 0,6 \mathrm{M}$ dan $1,0 \mathrm{M}$ dengan memvariasikan waktu kontak yaitu selama 4 hari, 8 hari, dan 12 hari. Untuk melihat pengaruh penambahan inhibitor dibuat larutan inhibitor dengan variasi konsentrasi $0,5 \%, 1 \%, 1,5 \%$, dan $2 \%$. Larutan inhibitor dicampur dengan medium $\mathrm{HCl} 0.2 \mathrm{M}$ dan $1.0 \mathrm{M}$ pada labu $50 \mathrm{~mL}$. Larutan ini digunakan sebagai pengujian pengaruh ekstrak daun papaya sebagai inhibitor [10].

\section{Metode Pengkuran}

\section{Analisis Kualitatif Ekstak Daun Pepaya}

Ekstrak methanol daun papaya dimasukkan ke dalam tabung reaksi. Beberapa tetes $\mathrm{FeCl}_{3}$ ditambahkan ke dalam tabung reaksi. Uji tannin dalam sampel positif apabila hasil menunjukan warna hijau kecoklatan atau biru kehitaman [12].

\section{Penentuan Kehilangan Berat}

Baja ST37 direndam dalam $50 \mathrm{~mL}$ larutan medium korosif $\mathrm{HCl}$ tanpa inhibitor dan adanya perbedaan konsentrasi dari inhibitor dengan variasi hari yaitu 4, 8, dan 12 hari. Kemudian dicuci dengan aseton, digosok, dan dikeringkan dengan oven pada suhu $60^{\circ} \mathrm{C}$. Berat baja sebelum $\left(\mathrm{m}_{1}\right)$ dan sesudah $\left(\mathrm{m}_{2}\right)$ direndam ditimbang dengan neraca analitik. Laju korosi, $v,\left(\mathrm{mg} / \mathrm{dm}^{2} / \mathrm{hari}\right)$ atau mdd, satuan ini digunkan karena massa jenis baja tidak diketahui. Sehingga $r$ dihitung dari hubungan berat awal baja, berat akhir baja setelah perendaman, luas permukaan baja, dan waktu perendaman, seperti pada persamaan 1 [10].

$$
v=\frac{m_{1}-m_{2}}{A x t}
$$

Keterangan:

$\begin{array}{ll}\mathrm{v} & \text { : Laju korosi }\left(\mathrm{mg} / \mathrm{cm}^{2} \text { hari }\right) \\ \mathrm{m}_{1} & \text { : Berat awal baja }(\mathrm{mg}) \\ \mathrm{m}_{2} & : \text { Berat akhir baja setelah perendaman }(\mathrm{mg}) \\ \mathrm{A} & \text { : Luas permukaan baja }\left(\mathrm{cm}^{2}\right) \\ \mathrm{T} & : \text { Waktu perendaman baja (hari) }\end{array}$

\section{Penentuan Efisiensi Inhibisi}

Persen efisiensi inhibisi pada korosi baja dapat dicari dengan persamaan [10]: 


$$
\mathrm{EI}=\frac{v_{\text {tanpa }} \text { inhibitor }}{-v_{\text {inhibitor }}} \times 100 \%
$$

Keterangan:

EI : Efisiensi inhibisi

\section{Penentuan Derajat Penutupan}

Derajat penutupan menunjukan bahwa banyaknya ekstrak yang teradsorbsi pada permukaan baja. Nilai derajat penutupan pada permukaan baja dapat dihitung melalui persamaan [11]:

$\varnothing=\frac{v_{\text {tanpa inhibitor }}-v_{\text {inhibitor }}}{v_{\text {inhibitor }}}$

Keterangan:

$\varnothing \quad$ : Derajat penutupan permukaan

\section{Pengukuran Polarisai Potensiodinamik}

Pada pengukuran potensiodinamik digunakan tiga elektroda yaitu elektroda pembantu yaitu elektroda $\mathrm{Pt}$, elektroda pembanding digunakan $\mathrm{Ag} / \mathrm{AgCl}$, dan baja sebagai elektroda kerja. Pengukuran polarisasi potensiodinamik dilakukan dalam medium $\mathrm{HCl}$ 1,0 M dan medium $\mathrm{HCl}$ yang mengandung ekstrak daun papaya sebagai inhibitor dengan variasi konsnetrasi yaitu $0,5 \%$, $1 \%, 1,5 \%$, dan $2 \%$. Ketiga elektroda dicelupkan ke dalam bejana berisi medium korosif $\mathrm{HCl}$ tanpa dan dengan adanya variasi konsentrasi ekstrak secara bergantian. Kemudian dihubungkan dengan potensiostat dan diatur potensial kerja sehingga diperoleh kurva hubungan antara potensial E Vs arus (I).

\section{Analisis Fotooptik}

Analisa fotooptik dilakukan dengan menganalisis permukaan baja yang direndam $\mathrm{HCl}$ tanpa dan dengan adanya penambahan ekstrak papaya sebagai inhibitor. Permukaan baja dikeringkan dan discan dengan Carton Stereo Trinocular Foto Optic [10].

\section{HASIL DAN PEMBAHASAN}

\section{Analisis Kualitatif Ekstrak Daun Pepaya}

Uji kualitatif dilakukan dengan menambahkan pereaksi spesifik tannin, $\mathrm{FeCl}_{3}$, ke dalam larutan ekstrak. Uji kualitatif ini digunakan untuk mengidentifikasi senyawa tannin yang terkandung di dalam ekstrak daun papaya. Ekstrak papaya postif mengandung tannin yang ditandai dengan terjadinya perubahan warna dari hijau pekat menjadi biru kehitaman [12].

\section{Analisis Pengujian Kehilangan Berat}

Analisis kehilangan berat dilakukan pada suhu kamar $\left(25^{\circ} \mathrm{C}\right)$. Gambar 1 memperlihatkan suatu pola yaitu dengan semakin tinggi konsentrasi asam klorida maka laju korosi $\left(\mathrm{mgcm}^{-2}\right.$ hari $\left.^{-1}\right)$ semakin meningkat. Hal ini dapat dilihat dari perendaman baja pada larutan medium
$\mathrm{HCl}$ dengan variasi konsentrasi 0,2M; 0,6M; dan 1,0 M. Perendaman juga dilakukan dengan adanya variasi waktu 4 hari, 8 hari, dan 12 hari.

Penelitian dilakukan dengan adanya perendaman baja dalam medium yang tidak mengandung asam klorida sebagai blanko. Dari variasi konsentrasi asam klorida dapat dilihat terjadinya peningkatan laju korosi. Semakin tinggi konsentrasi asam klorida maka laju korosi juga semakin meningkat dimana bagian dari permukaan baja yang terkorosi juga semakin banyak. Menurut Yetri, dkk [13], dalam penelitiannya menyatakan bahwa semakin lama waktu perendaman semakin banyak massa yang hilang sehingga akan meningkatkan laju korosi. Apabila konsentrasi asam klorida semakin tinggi maka jumlah atom Fe yang terlepas dari baja akan meningkat sehingga kecepatan korosi akan semakin besar. Laju korosi tertinggi terlihat pada konsentrasi asam klorida 1,0 M dengan perendaman selama 4 hari yaitu $25.933 \mathrm{mgcm}^{-}$ ${ }^{2}$ hari $^{-1}$.

Perendaman baja dilakukan dengan tiga variasi waktu yaitu 4 hari, 8 hari, dan 12 hari. Pada Gambar 1 dapat dilihat bahwa semakin lama waktu perendaman maka laju korosi $\left(\mathrm{mgcm}^{-2}\right.$ hari $\left.^{-1}\right)$ semakin menurun. Menurunnya laju korosi ini disebabkan oleh adanya pembentukan lapisan pasif yang relative lebih banyak pada waktu perendaman 12 hari jika dibandingkan 8 hari dan 4 hari. Lapisan pasif yang terbentuk pada permukan baja ini akan menghalangi masuknya ion-ion agresif ke permukaan baja sehingga akan mengurangi kecepatan korosi baja dalam larutan asam klorida [14]. Dengan demikian berdasarkan analisis laju korosi pada Gambar 1. untuk melihat pengaruh penambahan inhibitor dilakukan pada konsnetrasi $\mathrm{HCl}$ terendah dan tertinggi pada lama perendaman selama 4 hari.

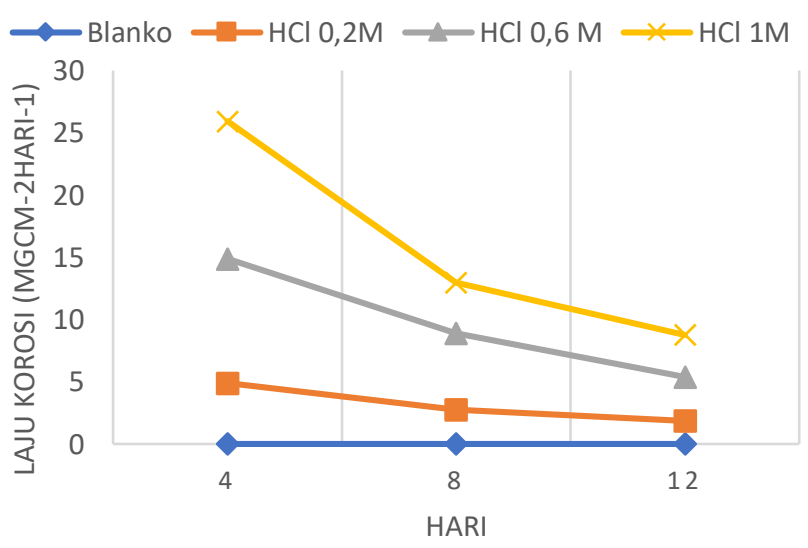

Gambar 1. Pengaruh lama perendaman (hari) terhadap laju korosi $\left(\mathrm{mgcm}^{-2}\right.$ hari $\left.^{-1}\right)$ baja pada larutan asam klorida pada variasi konsentrasi 0,$2 ; 0.6$; dan 1,0 M 


\section{Pengaruh Penambahan Ekstrak (\%) Terhadap Laju Korosi $\left(\mathrm{mgcm}^{-2}\right.$ hari $\left.^{-1}\right)$}

Metoda kehilangan berat juga dilakukan untuk mempelajari pengaruh inhibitor organic yaitu ektrak methanol daun papaya pada variasi konsentrasi $\mathrm{HCl}$. Inhibitor yang ditambahkan juga bervariasi yaitu $0,5 \%$; $1,0 \% ; 1,5 \%$, dan $2,0 \%$. Analisis ini dilakukan pada suhu kamar $\left(25^{\circ} \mathrm{C}\right)$. Gambar 2 menunjukan pengaruh variasi konsentrasi inhibitor (\%) pada konsentrasi $\mathrm{HCl} \mathrm{0,2} \mathrm{M}$ dan 1,0 M terhadap laju korosi $\left(\mathrm{mgcm}^{-2}\right.$ hari $\left.^{-1}\right)$.

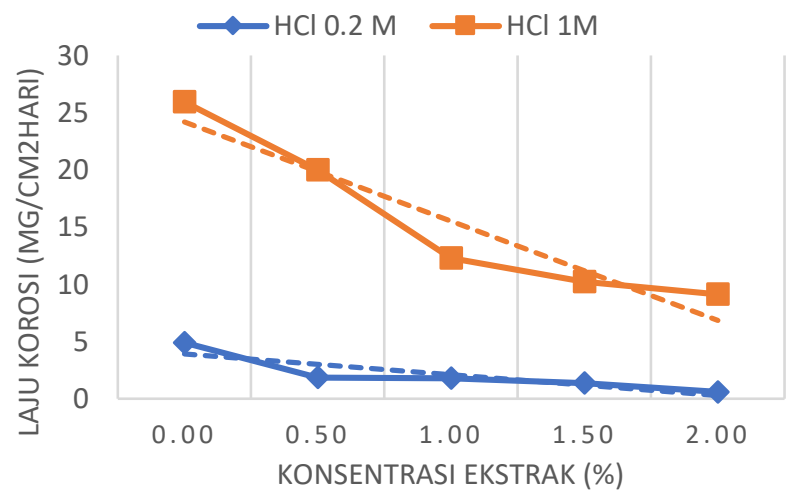

Gambar 2. Pengaruh konsentrasi ekstrak daun papaya (\%) terhadap laju korosi $\left(\left(\mathrm{mgcm}^{-2} \mathrm{hari}^{-1}\right)\right.$ baja dalam larutan asam klorida 0,2 $\mathrm{M}$ dan 1,0 M

Dari gambar 2 dapat dilihat terjadi penurunan laju korosi dengan adanya peningkatan konsentrasi inhibitor. Berdasarkan data analisis laju korosi baja ST37 tanpa penambahan inhibitor pada Gambar 1 mengalami penurunan laju korosi ketika ditambahkan ekstrak daun papaya. Sebelum ditambahkan inhibitor laju korosi baja ST37 pada medium $\mathrm{HCl}$ konsentrasi 0,2 M sebesar 4.893 $\mathrm{mgcm}^{-2}$ hari $^{-1}$ dan $\mathrm{HCl}$ 1,0 M sebesar $25.933 \mathrm{mgcm}^{-2}$ hari 1, setelah ditambahkan inhibitor dengan variasi konsnetrasi $0,5 \% ; 1,0 \%$; $1,5 \%$; dan $2 \%$ maka terjadi penurunan laju korosi seperti terlihat pada Gambar 3. Gambar 3 memperlihatkan pengaruh \% efisiensi inhibisi dengan variasi konsentrasi ekstrak daun papaya (\%) Hal ini menunjukan bahwa efisiensi inhibisi meningkat dengan adanya peningkatan konsentrasi ekstrak. Efisiensi tertinggi terdapat pada konsentrasi $\mathrm{HCl} \mathrm{0,2} \mathrm{M}$ dengan konsentrasi ekstrak $2 \%$ yang bernilai $87,8 \%$.

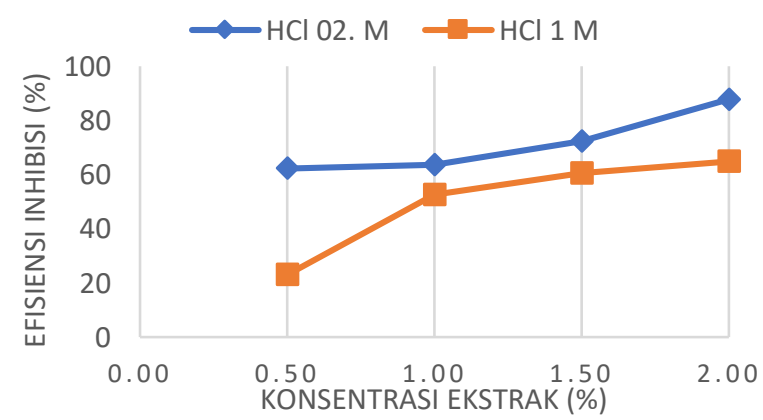

Gambar 3. Pengaruh konsentrasi ekstrak daun papaya (\%) terhadap Efisiensi Inhibisi (\%) korosi baja dalam larutan asam klorida 0,2 M dan 1,0 M
Menurunnya laju korosi dan meningkatnya efisiensi inhibisi dengan adanya variasi konsentrasi ekstrak disebabkan karena adanya penyerapan ekstrak daun papaya pada permukaan baja sehingga terbentuknya suatu lapisan pelindung. Lapisan pelindung ini berupa seyawa kompleks Fe dengan tanin. Tanin bertindak sebagai ligan karena memiliki pasangan electron bebas yang akan disumbangkan ke atom pusat Fe. Senyawa kompleks inilah yang akan melindungi permukaan baja dari serangan $\mathrm{Cl}^{-}$pada $\mathrm{HCl}[10]$.

Meningkatnya efisiensi inhibisi dari ektrak daun papaya yang ditunjukan dari analisis kehilangan berat mengindikasikan bahwa ekstrak daun papaya teradsorpsi pada permukaan baja. Efisiensi inhibisi yang tinggi pada konsentrasi ekstrak $2 \%$ menunjukaan jumlah ekstrak yang terserap juga semakin banyak.

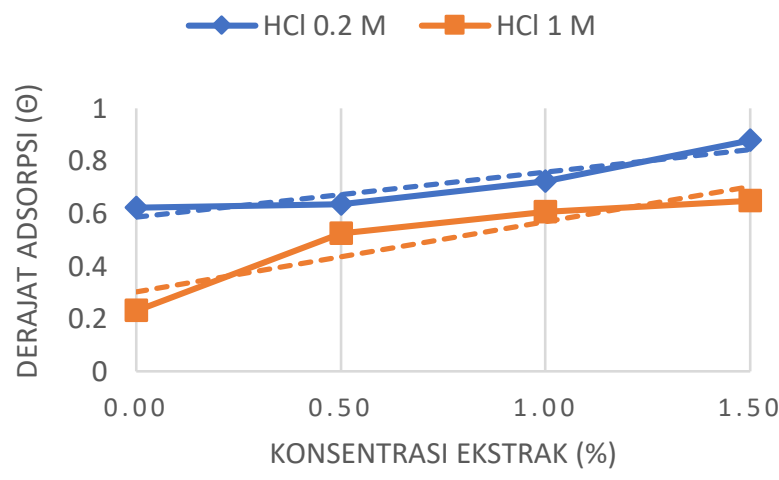

Gambar 4. Hubungan antara konsentrasi ekstrak (\%) dengan derajat penutupan $(\varnothing)$ pada larutan asam klorida $0,2 \mathrm{M}$ dan 1,0 $\mathrm{M}$

Dari Gambar 4 dapat dilihat nilai derajat penutupan permukaan $(\varnothing)$ tertinggi adalah sebesar 0,878 dengan konsentrasi ekstrak $2 \%$ pada konsentrasi $\mathrm{HCl} \mathrm{0,2} \mathrm{M}$. Pada $\mathrm{HCl}$ 1,0 M nilai derajat penutupan tertinggi adalah 0,6484 dengan konsentrasi inhibitor 2\%. Hal ini menunjukkan bahwa pada konsentrasi inhibitor $2 \%$ ekstrak daun papaya menutupi permukaan baja lebih banyak dengan membentuk suatu lapisan pelindung.

\section{Pengukuran Polarisasi Potensiodinamik}

Pengukuran polarisasi potensiodinamik diperoleh kurva hubungan antara potensial $(\mathrm{mV})$ dengan $\log$ arus $(\mathrm{mA})$. Polarisasi potensiodinamik menunjukkan terjadinya interaksi antarmuka antara larutan dengan elektroda. Interaksi ini menimbulkan polarisasi dan arus tertentu. Kurva polarisasi diekstrapolasikan dengan metoda Tafel untuk menentukan nilai arus korosi (Ikorosi), potensial korosi (Ekorosi) dan efisiensi inhibisi (\%EI). Data analisis Tafel plot dapat dilihat pada Tabel 1. 
Berdasarkan data ektrapolasi Tafel plot pada Tabel 1 dapat dilihat reaksi terjadi antara anodic dan katodik. Reaksi di anodic dan katodik dihambat dengan adanya ekstrak daun papaya dan efisiensi inhibisi korosi baja meningka dengan meningkatnya konsentrasi dari ekstrak daun papaya. Ekstrak daun papaya menunjukaan bahwa ekstrak tersebut berperan sebagai inhibitor campuran. Hal ini disebabkan oleh terjadinya pergeseran nilai potensial kearah anodic dan katodik. Pergeseran nilai potensial korosi kearah anodic dan katodik menunjukan adosorpsi molekul ekstrak daun papaya pada permukaan baja [15].

Tabel 1. Nilai potensial dan arus korosi baja dari ektrapolasi Tafel plot tanpa dan adanya penambahan ekstrak daun pepaya

\begin{tabular}{cccc}
\hline $\begin{array}{c}\text { Konsentrasi } \\
\text { ekstrak }(\%)\end{array}$ & $\mathrm{E}_{\text {korosi }(\mathrm{mV})}$ & $\mathrm{I}_{\text {korosi }}\left(\mathrm{mA} / \mathrm{cm}^{2}\right)$ & $\begin{array}{c}\mathrm{EI} \\
(\%)\end{array}$ \\
\hline 0 & -0.43 & 0.0266 & - \\
0.5 & -0.585 & 0.0158 & 40.6 \\
1 & -0.39 & 0.0105 & 60.53 \\
1.5 & -0.42 & 0.0064 & 75.94 \\
2 & -0.38 & 0.0049 & 81.58 \\
\hline
\end{tabular}

Konsentrasi ekstrak daun papaya dan nilai arus korosi memiliki hubungan berbanding terbalik. Hal ini dapat dilihat nilai arus korosi akan menurun seiring dengan meningkatnya konsentrasi ekstrak daun papaya yang ditambahkan. Menurunnya arus korosi disebabkan karena pergerakan electron yang terdapat dipermukaan baja akan semakin sedikit yang teroksidasi dalam medium asam klorida. Hal ini disebabkan ekstrak daun papaya menutupi permukaan baja tersebut. Nilai efisiensi inhibisi meningkat dengan meningkatnya konsentrasi dari ekstrak daun papaya. Efisiensi inhibisi korosi baja dalam medium $\mathrm{HCl} 1 \mathrm{M}$ dengan adanya ekstrak daun papaya konsentrasi $2 \%$ mencapai $81.58 \%$.

\section{Analisis Foto Optik}

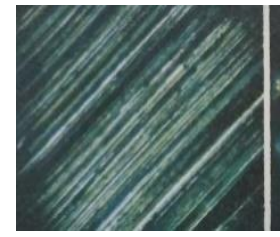

$\mathbf{a}$

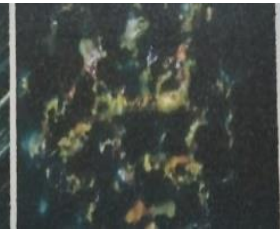

b

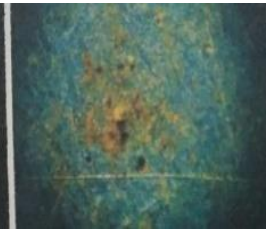

c
Gambar 5. Hasil fotooptik permukaan baja dengan perbesaran 100x a. Tanpa perlakuan b. Pada larutan $\mathrm{HCl} 1 \mathrm{M}$ c. Pada larutan $\mathrm{HCl} 1 \mathrm{M}+2 \%$ ekstrak

Gambar 5(a) merupakan foto permukaan baja ST37 pada 100x perbesaran yang belum diberi perlakukan perendaman dengan medium korosif $\mathrm{HCl}$. Permukaan baja tersebut masih terlihat mulus, tidak berlubang, dan pori-pori pada permukaan baja belum terlihat. Gambar 5(b) merupakan foto permukaan baja yang telah 52 Putri and Akbar direndam dengan medium korosif $\mathrm{HCl} 1 \mathrm{M}$. Dari gambar dapat dilihat bahwa permukaan baja mengalami korosi yang ditandai dengan warna coklat pada permukaan baja akibat karat karena adanya interaksi $\mathrm{H}+$ dan $\mathrm{Cl}$ - pada permukaan baja sehingga mengakibatkan permukaan baja berlubang dan berpori. Gambar 5(c) dapat terlihat bahwa lapisan permukaan baja yang direndam dalam medium korosif yaitu $\mathrm{HCl} 1 \mathrm{M}$ dengan adanya penambahan ekstrak daun papaya $2 \%$ tidak mengalami kerusakan yang lebih parah dibandingkan dengan baja yang direndam dengan medium korosif saja. Hal ini disebabkan karena ekstrak daun papaya yang berperan sebagai inhibitor, teradsoprsi pada permukaan baja sehingga membentuk suatu lapisan pelindung. Lapisan pelindung tersebut berperan menghalangi terjadinya interaksi antara baja dengan asam klorida sehingga hanya Sebagian kecil permukaan baja yang mengalami korosi.

\section{KESIMPULAN}

Setelah dilakukan penelitian dapat disimpulkan bahwa ekstrak daun papaya dapat digunakan sebagai inhibitor korosi. Hal ini dapat dilihat dengan semakin tinggi konsnetrasi inhibitor maka laju korosi akan menurun. Efisiensi inhibisi tertinggi adalah $87.8 \%$ pada konsentrasi $\mathrm{HCl}$ 0.2 M dengan konsentrasi ekstrak 2\%. Dari analisis potensiodinamik didapatkan arus korosi yang semakin menuru setelah ditambahkan ekstrak daun papaya. Analisis fotooptik menunjukaan bahwa terjadinya perbedaan permukaan baja yang telah terkorosi pada medium $\mathrm{HCl} 1 \mathrm{M}$ dan baja pada medium $\mathrm{HCl}+$ inhibitor $2 \%$.

\section{DAFTAR PUSTAKA}

[1] Adhi Setiawan, Novi Eka Mayangsari, Denny Dermawan Pemanfaatan Ekstrak Daun Tembakau sebagai Inhibitor Korosi pada Logam Baja Karbon dan Aluminium. 2018.

[2] Setiawan, A., Novitrie, N. A., \& Ashari, L. Analisis Korosi Logam Tembaga dan Aluminium pada Biodiesel yang Disintesis dari Minyak Goreng Bekas. Seminar MASTER, tanggal 21 Nopember 2017. Surabaya: Politeknik Perkapalan Negeri Surabaya, 2017.

[3] A. Azhari, "Pengaruh Proses Tempering dan Proses Pengerolan Di bawah dan Di atas Temperatur Rekristalisasi pada baja karbon Sedang Terhadap Kekerasan dan Ketangguhan Serta Struktur Mikro untuk Mata Pisau Pemanen Sawit,” J. Tek. Mesin, vol. 2, no. 2, pp. 10-22, 2012.

[4] Nika Khumaidah ,Ediman Ginting Suka dan Syafriadi. Inhibisi Korosi Ekstrak Buah Pinang (ARECA CATECHU L.) Sebagai Penghambat 
Laju Korosi Pada Baja Karbon Rendah C-Mn Steel dengan Medium Korosif HCL dan NaCl. 2019.

[5] Saputro. FD, Sutjahjo, D.H. Variasi Media Pengkorosian dan Waktu Terhadap Laju Korosi [ada Logam Baja Rendah Karbon (Mild Steel) dengan Pemodelan Kondisi Sirip Kemudi. JTM Vol (05) No 03, 59-66. 2017.

[6] Mehdipour, M., Ramezanzadeh, B., \& Arman, S. Y. Electrochemical Noise Investigation of Aloe Plant Extract as Green Inhibitor on The Corrosion of Stainless Steel in $1 \mathrm{M} \mathrm{H}$ 2SO4. J. of Industrial and Engineering Chemistry, 21, 318-327, 2018.

[7] Liao, L. L., Mo, S., Luo, H. Q., \& Li, N. B. Corrosion Protection for Mild Steel by Extract from The Waste of Lychee Fruit in $\mathrm{HCl}$ Solution: Experimental and Theoretical Studies.Journal of Colloid and Interface Science, 520, 41-49, 2018.

[8] Yaro, A. S., Khadom, A. A., \& Wael, R. K. Apricot Juice as Green Corrosion Inhibitor of Mild Steel in Phosphoric Acid. Alexandria Engineering Journal, 52, 129-135, 2013.

[9] A'yun, Q. Laily, A.N. Analisis Fitokimia Daun Pepaya (Carica papaya L.) di Balai Pnelitian Tanaman Aneka Kacang dan Umbi. Seminar Nasional Konservasi dan Oemanfaatan Sumber Daya Alam. 2015.

[10] M.Erna, Emriadi, A.Alif, S.Arief. Karboksimetil Kitosan sebagai Inhibitor Korosi pada Baja Lunak dalam Media Air Gambut. Jurnal Matematika dan Sains. 16(2) : 106-110, 2011.

[11] Verma, C., Ebenso, E. E., \& Quraishi, M. A. Corrosion Inhibitors for errous and Non-Ferrous Metals and Alloys in Ionic Sodium Chloride Solutions: A Review. Journal of Molecular Liquids, 248, 927-942, 2017.

[12] Desinta, T. Penentuan Jenis Tanin Secara Kualitatif dan Penetapan Kadar Tanin dari Kulit Buah Rambutan Secara Permanganometri. Jurnal Ilmiah Mahasiswa Universitas Surabaya. Vol (4) No.1. 2015.

[13] Y.yuli, Emriadi, Jamarun.N, Gunawarman. Efisiensi Inhibisi Korosi Mild Steel Lunak dalam Media Asam dengan Inhibitor Ekstrak Kulit Buah Kakao. Jurnal Riset Teknologi Pencegahan Pencemaran Industri. Vol (7) No.2, 2016.

[14] Asdim. Penentuan Efisiensi Inhibisi Ekstrak Kulit Buah Manggis (Garcinia Mangostana L) pada Reaksi Korosi Baja Dalam Larutan Asam. Jurnal Gradien Vol.3 No 2:273-276, 2001.

[15] Nahle, Ayssar; Abu-Abdom, Idelsan; AbdelRahman, Ibrahim dan Al-Khayat, Maysoon. UAE Neem Extract as a Corrosion Inhibitor for Carbon Steel in HCl Solution of Corrosion, 2010. 